\title{
An assessment of wind forcing impact on a spectral wave model for the Indian Ocean
}

\author{
P G Remya ${ }^{1, *}$, Raj KumaR ${ }^{2}$ and Sujit Basu ${ }^{2}$ \\ ${ }^{1}$ Information Services and Ocean Sciences Group, Indian National Centre for Ocean Information Services, \\ "Ocean Valley", Pragathi Nagar (BO), Nizampet (SO), Hyderabad 500 090, India. \\ ${ }^{2}$ Atmospheric and Oceanic Sciences Group, Space Applications Centre (ISRO), Ahmedabad 380 015, India. \\ ${ }^{*}$ Corresponding author. e-mail: remyabijeshh@gmail.com
}

The focus of the present study is the assessment of the impact of wind forcing on the spectral wave model MIKE $21 \mathrm{SW}$ in the Indian Ocean region. Three different wind fields, namely the ECMWF analyzed winds, the ECMWF blended winds, and the NCEP blended winds have been used to drive the model. The wave model results have been compared with in-situ observations and satellite altimeter data. This study also evaluated the performance of the wind products during local phenomenon like sea breeze, since it has a significant impact on the wave prediction in the Indian coastal region. Hence we explored the possibility of studying the impact of diurnal variation of winds on coastal waves using different wind fields. An analysis of the model performance has also been made during high wind conditions with the inference that blended winds generate more realistic wave fields in the high wind conditions and are able to produce the growth and decay of waves more realistically.

\section{Introduction}

The knowledge of wave conditions is vital for all marine related activities such as shipping, fishing, offshore and coastal structure constructions, and naval operations. Wave modeling has reached satisfactory level for practical applications with the development of third generation wave models (e.g., Komen et al. 1994). Advances in weather forecasting and remote sensing of winds over the oceans contributed towards this as the wave models compute the wave field from surface winds, provided mostly by atmospheric models (e.g., Bidlot et al. 2002). The performance of wave model simulations, whether for research or operational forecasting, depends on the quality of the driving wind fields. Cavaleri (1994) clearly showed the direct dependence of significant wave height $\left(\mathrm{H}_{\mathrm{s}}\right)$ on wind speed through an empirical relation for a fully developed sea. Past study conducted by Kumar et al. (2000), for the Indian Ocean, confirmed that wave height and wave period predictions are dependent on the precision of the wind forcing used to drive the model. Kumar et al. (2000) also concluded that the error in the wave hindcast/forecast increases with decreasing frequency of wind forcing. Feng et al. (2006) have conducted a very detailed study related to the impact of wind forcing on a global wind-wave model. The results of this study suggest that the model output is critically dependent on the choice of wind field product. The present work, although following the methodology of Feng et al. (2006), differs from it by aiming to study the impact of three different wind products on the spectral wave model MIKE 21 SW for the Indian Ocean region. Another differing aspect of

Keywords. MIKE21 SW; altimeter; sea breeze; wind forcing. 
the present work is the study of the impact of diurnal variation of winds in the coastal regions. The assessment of the impact has been carried out using in-situ observations as well as satellite data. As far as the Indian Ocean is concerned, an accurate wave prediction during tropical cyclone condition is a challenging task. Accordingly, experiments have been conducted to evaluate the performance of three wind products during high wind conditions. Thus, the central theme of the study is identification of the wind field, which, in conjunction with the wave model under consideration, would produce the best wave predictions in the Indian Ocean.

The MIKE21 SW model was forced with three different winds, and synoptic maps of wave parameters were generated. The study was carried out for the Indian Ocean region for the year 2005. Initially the model derived wave parameters were compared with the same parameters observed by moored buoys deployed by the National Institute of Ocean Technology (NIOT). Unfortunately, the available buoy data were sparse and discontinuous. Hence, for a comprehensive analysis, the model derived wave parameters were compared with collocated satellite altimeter data and statistical error analysis was carried out for the Indian Ocean.

\section{Methodology}

\subsection{Wave model: MIKE $21 S W$}

MIKE $21 \mathrm{SW}$ is a new generation spectral wind wave model, based on unstructured meshes, and is developed by Danish Hydraulic Institute (DHI 2005). The model simulates growth, decay, and transformation of wind generated waves and swells in offshore and coastal areas. In this model, the wind waves are represented by the action density spectrum $N(\sigma, \theta)$. The independent parameters chosen are the relative (intrinsic) angular frequency, $\sigma=2 \pi f$, and the direction of wave propagation, $\theta$. The governing equation is the wave action balance equation formulated in either Cartesian or spherical co-ordinates (Komen et al. 1994; Young 1999).

$$
\frac{\partial N}{\partial t}+\nabla \cdot(\vec{v} N)=\frac{s}{\sigma}
$$

where $N(\vec{x}, \sigma, \theta, t)$ is the action density, $t$ is the time, $\vec{x}=(x, y)$ is the two dimensional radius vector, $x, y$ being the Cartesian co-ordinates, $\vec{v}=\left(c_{x}\right.$, $\left.c_{y}, c_{\sigma}, c_{\theta}\right)$ is the propagation velocity of a wave group in the four-dimensional phase space formed by $\vec{x}, \sigma$ and $\theta$. Finally, $s$ is the source term for the energy balance equation.
MIKE $21 \mathrm{SW}$ model is based on a flexible mesh, which allows for coarse spatial resolution in the offshore area and high resolution in the shallow coastal waters. MIKE21 SW model includes two different formulations: a directional decoupled parametric formulation and a fully spectral formulation of the wave action balance equation. The first formulation is suitable only for near shore conditions, whereas the second one is applicable in both near shore and offshore regions. Hence, in this study the second formulation has been used, as the study area contains both shallow and offshore regions. In the fully spectral formulation the source functions are based on the WAM Cycle 4 formulation (Komen et al. 1994). The source term for depth limited wave breaking is based on the formulation by Battjes and Janssen (1978). A short description of the source term can be found in Sørensen et al. (2004). In the present study, the model domain covers the Indian Ocean region $\left(60^{\circ} \mathrm{S}-25^{\circ} \mathrm{N} ; 40^{\circ}-100^{\circ} \mathrm{E}\right)$. For the model runs, the spatial resolution has been chosen to be $0.25^{\circ}$ in the coastal waters and $1^{\circ}$ for the rest of the region (figure 1). This, however, does not mean that the resolution is constant everywhere in this domain. MIKE21 SW model uses a flexible mesh bathymetry for model runs. The flexible mesh allows fine resolution near

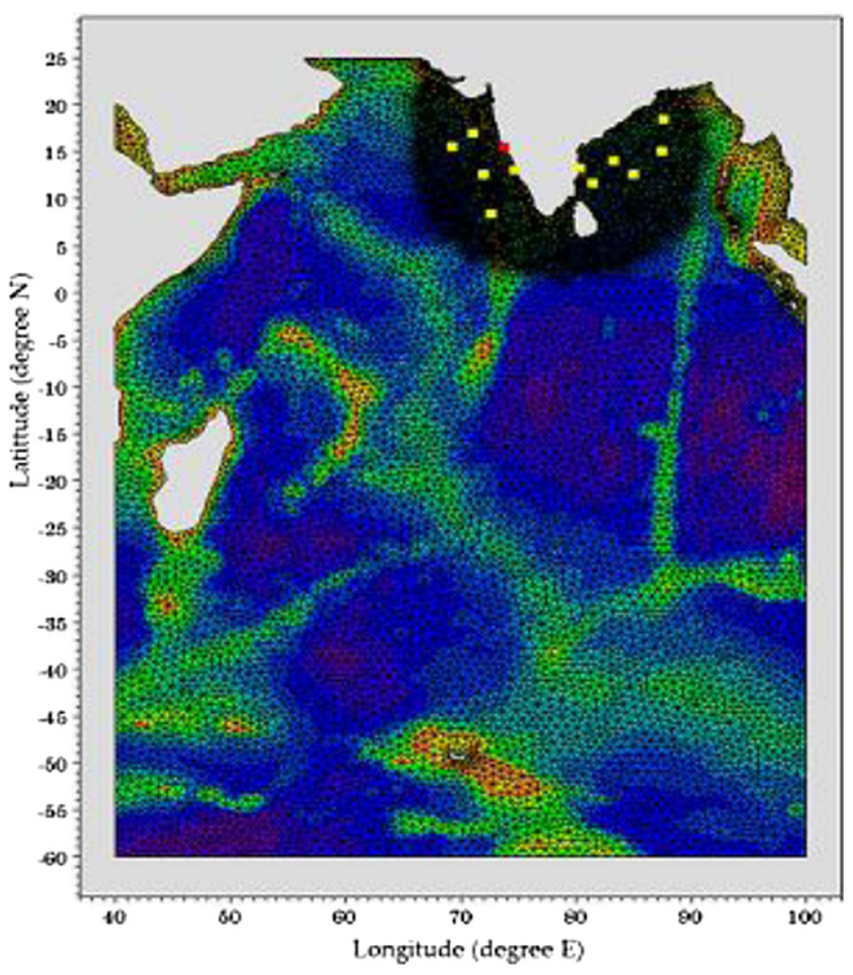

Figure 1. Map of the study area showing flexible mesh grid and buoy locations. 
the coast. The bathymetry is from GEBCO (General Bathymetric Charts of the Ocean) produced by Intergovernmental Oceanographic Commission (2003). The resolution of GEBCO bathymetry grid is $1 \times 1$ minute. Model runs have been made with three wind forcing fields from three different sources. The model was initialized over a 7-day period to arrive at a stationary model output, and thereafter experiments were performed for the entire year of 2005. The model run contains no assimilation of altimeter or buoy wave height observations.

\subsection{Wind forcing fields}

The present study used three different wind field products from three different sources. The same temporal resolution of the three wind fields made comparison more homogenous and meaningful. The first wind field used in the study is 6-hourly (viz., 00, 06, 12, and 18 UTC) zonal (U) and meridional $(\mathrm{V})$ components of winds at $10 \mathrm{~m}$ height derived from European Centre for Medium-Range Weather Forecast (ECMWF) for 2005. The horizontal resolution of ECMWF analysis is $0.5^{\circ} \times$ $0.5^{\circ}$ along latitude and longitude. For generating analyzed wind fields ECMWF utilizes a four dimensional (4-D) variational assimilation scheme to assimilate various meteorological observations (Persson and Grazzini 2007).

The second and third wind fields used in this study are blended wind fields from two different sources. The first blended wind field is obtained from IFREMER, France. This wind field is derived through a spatial blending of the high resolution QSCAT scatterometer winds with ECMWF model winds. The wind data are available at a spatial resolution of $0.25^{\circ}$ in longitude and latitude. The quality of the blended winds showed encouraging results in comparison with buoy winds (Bentamy et al. 2007). They found that the correlation coefficients between buoy winds and blended winds were of the order of $0.80-0.90$ and RMS differences were $<2 \mathrm{~m} / \mathrm{s}$.

The second blended wind field product is a blend of QSCAT scatterometer winds and NCEP reanalysis surface wind datasets (Chin et al. 1998; Milliff et al. 1999). This dataset consists of global 6-hourly maps at $0.5^{\circ}$ spatial resolution. The blending scheme provides 6-hourly global fields by retaining QSCAT wind retrievals in swath regions, and by augmenting in the unsampled regions the lowwave number NCEP fields with a high-wave number component that is based on monthly QSCAT statistics. For highest data quality, rain-flagged wind vector cells (WVC) in the QSCAT record were excluded from the blending scheme. Details of the effect of rain on QSCAT wind retrievals are described in Milliff et al. (2004).

For convenience, the abbreviations EC, EQ, NQ, and SW are used hereafter for representing ECMWF winds, QSCAT+ECMWF blended winds, QSCAT+NCEP blended winds and MIKE 21 SW model respectively. Moreover, the abbreviations SW-EC, SW-EQ and SW-NQ are used to denote the wave parameters obtained from the model driven by one of these three wind fields, respectively.

(a)
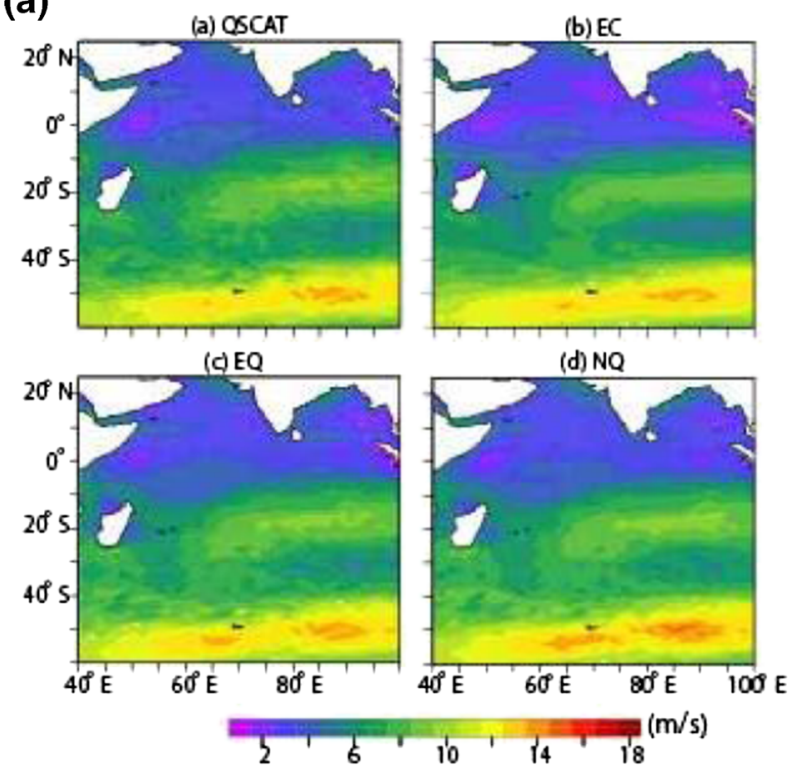

(b) (a) EQ-EC

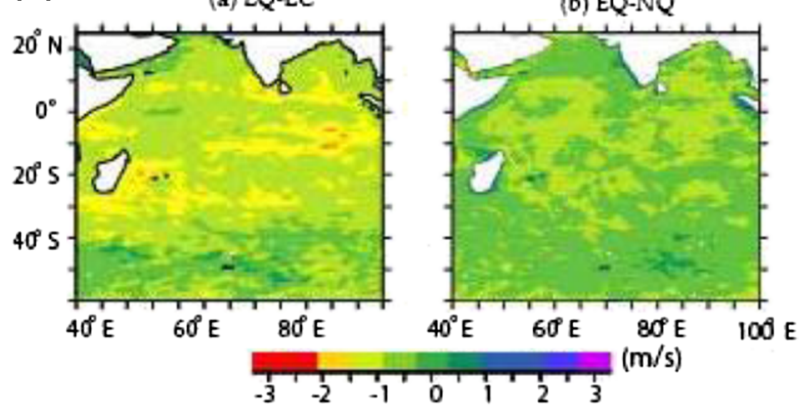

(c)

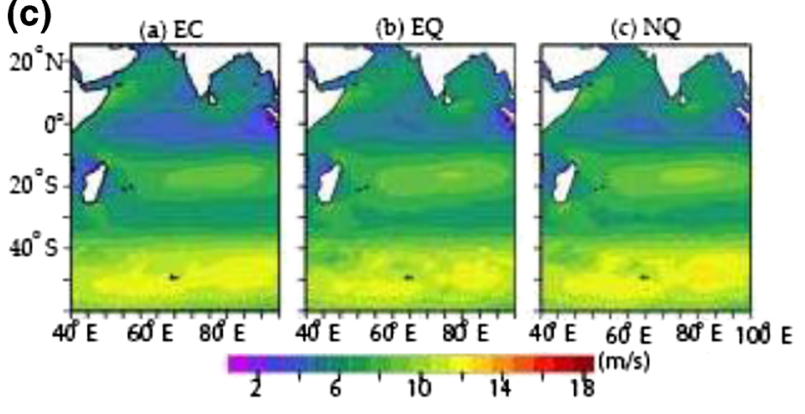

Figure 2. (a) Monthly mean wind speed maps for April 2005. (b) Monthly mean wind speed difference map (EQ-EC and EQ-NQ). (c) Mean wind speed maps for the year 2005. 


\subsection{Model evaluation using in-situ observations and altimeter data}

As mentioned earlier, 3-hourly wave data derived by moored buoys deployed by the National Institute of Ocean Technology (NIOT) have been used for validating the model results. The locations of buoys are shown in figure 1. Apart from in-situ data, remotely sensed data from satellite altimeter have also been used. The JASON 1 satellite system carrying a state-of-the-art altimeter sensor, launched on December 7, 2001, was providing wind and wave information over the global oceans regularly till 2013. Radar altimeter data have been provided by the Delft Institute for Earth Oriented Space Research Radar Altimeter Data base system. Model-estimated wave data, and altimeter derived wave data have been collocated and this collocation resulted in more than 0.736 million data pairs. The selected wind speed range for the comparison was $2-20 \mathrm{~m} / \mathrm{s}$. Although the altimeter does not provide direct measurement of ocean wave period, there are algorithms to estimate this parameter from altimeter observations. This study also used one such recently developed algorithm by Govindan et al. (2011). The zero crossing period, $T_{\mathrm{z}}=\sqrt{m_{0} / m_{2}}$, is the average time interval between similar direction crossings of mean water level for a wave record. The zero crossing surface wave period based on altimeter is computed as:

$$
\mathrm{T}_{\mathrm{zalt}}=\frac{\xi-5.78}{\xi+\left(\mathrm{ws} /\left(\mathrm{H}_{\mathrm{s}} *\left(\left(\mathrm{ws} / \mathrm{H}_{\mathrm{s}}\right) \mathrm{H}_{\mathrm{s}}\right)\right)\right)}+\mathrm{H}_{\mathrm{s}}+5.70
$$

where ws is the wind speed and $\xi$ is the wave age, $\xi=3.25\left(\mathrm{H}_{\mathrm{s}}^{2} \mathrm{~g}^{2} / \mathrm{ws}^{4}\right)^{0.31}$.

Various statistical measures like bias, root mean square error (RMSE), scatter index (SI), and correlation coefficient $(R)$ are used to assess the model performance by comparing the model derived parameters with the corresponding buoy/altimeter observations.

\section{Results and discussions}

The model simulations were performed for the year 2005 using three different wind fields and the hourly synoptic maps of wave parameters were generated. Before the wave parameter comparison, the difference in the three wind products has to be investigated in detail for a better comprehension of the wave model results. Assuming that QSCAT wind represents truth, a comparison of the three wind fields has been done with QSCAT winds. Although we compared the monthly means of the three wind fields with the QSCAT monthly means for all the 12 months, the results are shown for only one representative month (April 2005). Figure 2(a) shows this comparison. In the comparison, both the blended winds showed the fine scale features of wind fields present in the QSCAT winds whereas the EC wind fields completely missed these fine features. The comparison of wind speed shows smoothed wind fields and clear underestimation of wind speed all over the domain except at the southernmost latitudes of the domain for EC winds (figure $2 \mathrm{~b}$ ). In the southernmost latitude, EC winds show a spread of high wind regime. Among the two blended winds more geographical variability was visible in EQ wind. Both NQ and EQ winds show a good agreement with QSCAT winds and also with each other except at the coastal regions. At the coastal regions EQ winds were very weak. The difference was around $2 \mathrm{~m} / \mathrm{s}$ in the western coast of India (figure $2 \mathrm{~b}$ ). This comparison also shows how well the blending works in both winds. Figure 2(c) shows the one year mean of the three different winds. The difference in the yearly mean

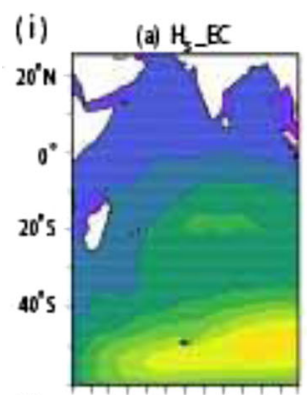

(ii)

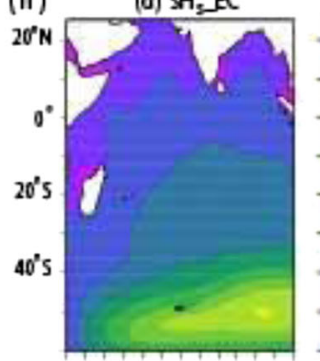

(iii)

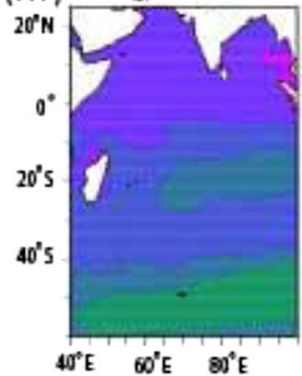

(b) $\mathrm{H}_{3}-\mathrm{EQ}$

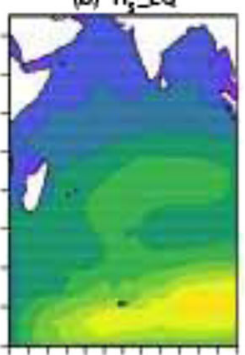

(e) $\mathrm{SH}_{\mathrm{b}} \mathrm{EQ}$

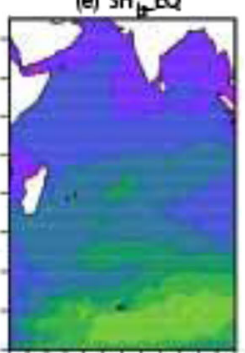

(h) $\mathrm{WH}_{2}, \mathrm{EQ}$

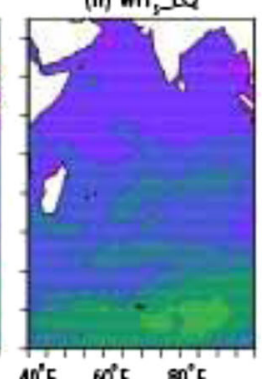

$40^{\prime \prime} \mathrm{E} \quad 0^{\circ} \mathrm{E} \quad 80^{\circ} \mathrm{E}$

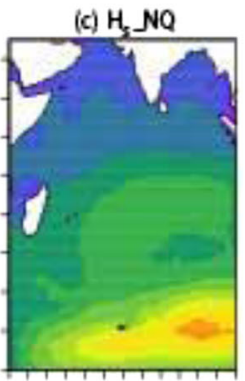

(f) $\mathrm{SH}, \mathrm{NQ}$

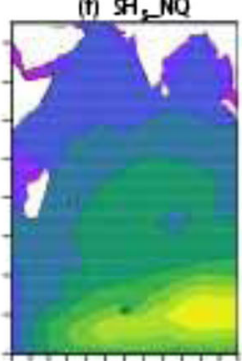

(i) $W H_{2} \mathrm{NQ}$

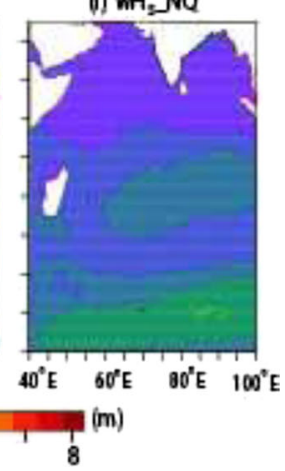

Figure 3. Model derived monthly mean wave height maps for April 2005. (i) Significant wave height $\left(\mathrm{H}_{\mathrm{S}}\right)$; (ii) swell height $\left(\mathrm{sH}_{\mathrm{s}}\right)$; and (iii) wind sea height $\left(\mathrm{wH}_{\mathrm{s}}\right)$. 
is also in agreement with the differences observed in the monthly means.

An analysis of monthly means of wave parameters like significant wave height $\left(\mathrm{H}_{\mathrm{s}}\right)$, swell height $\left(\mathrm{sH}_{\mathrm{s}}\right)$, wind sea height $\left(\mathrm{wH}_{\mathrm{s}}\right)$ and wave period $\left(\mathrm{T}_{\mathrm{m}}\right)$ has been carried out to see the sensitivity of the wave model to the differences in the wind fields. Figure 3 shows the monthly mean of the wave parameters. From this figure it can be seen that the monthly mean $\mathrm{SW}-\mathrm{EC} \mathrm{H}_{\mathrm{s}}$ is missing fine scale features compared to SW-EQ $\mathrm{H}_{\mathrm{s}}$ and $\mathrm{SW}-\mathrm{NQ} \mathrm{H}_{\mathrm{s}}$ as in the case of wind fields. SW-EQ $\mathrm{H}_{\mathrm{s}}$ and SWEC $\mathrm{H}_{\mathrm{s}}$ are more or less the same whereas the SW$\mathrm{NQ} \mathrm{H}_{\mathrm{s}}$ was high compared to the other two. These are the preliminary findings from the comparison of monthly means. Further assessment of the authenticity of the wind fields is done by comparing the simulated wave parameters for the three different wind products with observations.

\subsection{Evaluation of wave parameters using in-situ and remote sensing observations}

The model performance has been evaluated in terms of $\mathrm{H}_{\mathrm{s}}, \mathrm{sH}_{\mathrm{s}}, \mathrm{wH}_{\mathrm{s}}$ and $\mathrm{T}_{\mathrm{m}}$ in both Arabian Sea (AS) and Bay of Bengal (BOB) by selecting six buoys from each basin. For the comparison with buoy data, 3-hourly time series of simulated wave parameters at the selected buoy locations were used. For the buoys the wave spectrum measurements between 0.04 and $0.1 \mathrm{~Hz}$ are considered to be low frequency (swell) components and those between 0.1 and $0.5 \mathrm{~Hz}$ are labeled as high frequency (sea) components. The same criteria are adopted for the sea-swell separation in the model spectra. The formulae of significant wave height and mean wave period from the buoy are $\mathrm{T}_{\mathrm{m}}=\sqrt{m_{0} / m_{2}}$ and $\mathrm{H}_{\mathrm{s}}=$ $\sqrt[4]{m_{0}}$. In table 1 , the results for the Arabian Sea and the Bay of Bengal have been shown for the 12 buoys. There were more than 19,000 data points. From the statistics of comparison it can be seen that EC winds show a lower RMSE as well as SI while at the same time showing a negative bias. The negative bias signifies the underestimation of wind speed as observed in the comparison of mean wind fields. The EQ wind had minimum bias and maximum error. NQ had a high positive bias but it showed a good agreement in standard deviation with buoy. From table 1 we can also see that the RMSE of $\mathrm{H}_{\mathrm{s}}$ is low for the EQ winds although the corresponding RMSE of winds was comparatively high. The reason for this may be the tuning of the MIKE 21 SW model with EQ winds.

The negative bias in the $\mathrm{EC}$ wind speed induced a negative bias in SW-EC $\mathrm{H}_{\mathrm{s}}$ also. The RMSE and SI of the SW-EQ $\mathrm{H}_{\mathrm{s}}$ and SW-EC $\mathrm{H}_{\mathrm{s}}$ are more or less the same. In the case of bias, SW-EQ $\mathrm{H}_{\mathrm{s}}$ and $\mathrm{SW}-\mathrm{NQ} \mathrm{H}_{\mathrm{s}}$ show a high positive bias. A close look into the error statistics of swell and sea components confirms that the positive bias of $\mathrm{H}_{\mathrm{s}}$ is mainly because of a high positive bias present in

Table 1. Error statistics for the Buoy comparison.

\begin{tabular}{|c|c|c|c|c|c|c|c|}
\hline & & Bias & RMSE & SI & $r$ & Mean & Std \\
\hline \multirow[t]{4}{*}{ Wind speed (m/s) } & Buoy & & & & & 5.33 & 2.89 \\
\hline & SW-EC & -0.31 & 1.70 & 0.32 & 0.82 & 5.02 & 2.66 \\
\hline & SW-EQ & -0.04 & 2.06 & 0.39 & 0.76 & 5.29 & 3.06 \\
\hline & SW-NQ & 0.52 & 1.99 & 0.37 & 0.78 & 5.85 & 2.85 \\
\hline \multirow[t]{4}{*}{$\mathrm{H}_{\mathrm{s}}(\mathrm{m})$} & Buoy & & & & & 1.46 & 0.91 \\
\hline & SW-EC & -0.04 & 0.36 & 0.24 & 0.93 & 1.41 & 0.73 \\
\hline & SW-EQ & 0.12 & 0.34 & 0.24 & 0.93 & 1.57 & 0.84 \\
\hline & SW-NQ & 0.26 & 0.43 & 0.30 & 0.93 & 1.72 & 0.86 \\
\hline \multirow[t]{4}{*}{$\mathrm{wH}_{\mathrm{s}}(\mathrm{m})$} & Buoy & & & & & 1.18 & 0.73 \\
\hline & SW-EC & -0.08 & 0.28 & 0.24 & 0.93 & 1.10 & 0.63 \\
\hline & SW-EQ & 0.01 & 0.26 & 0.22 & 0.93 & 1.19 & 0.69 \\
\hline & SW-NQ & 0.08 & 0.30 & 0.25 & 0.92 & 1.26 & 0.66 \\
\hline \multirow[t]{4}{*}{$\mathrm{sH}_{\mathrm{S}}(\mathrm{m})$} & Buoy & & & & & 0.80 & 0.63 \\
\hline & SW-EC & 0.03 & 0.37 & 0.47 & 0.81 & 0.83 & 0.56 \\
\hline & SW-EQ & 0.16 & 0.38 & 0.47 & 0.85 & 0.96 & 0.62 \\
\hline & SW-NQ & 0.29 & 0.46 & 0.57 & 0.85 & 1.09 & 0.66 \\
\hline \multirow[t]{4}{*}{$\mathrm{T}_{\mathrm{m}}(\mathrm{s})$} & Buoy & & & & & 5.67 & 1.36 \\
\hline & SW-EC & 0.18 & 0.94 & 0.17 & 0.76 & 5.85 & 1.28 \\
\hline & SW-EQ & 0.40 & 1.03 & 0.18 & 0.74 & 6.07 & 1.28 \\
\hline & SW-NQ & 0.57 & 1.11 & 0.20 & 0.75 & 6.25 & 1.36 \\
\hline
\end{tabular}


the $\mathrm{sH}_{\mathrm{s}}$. The RMSE, SI and bias for the $\mathrm{sH}_{\mathrm{s}}$ are high in all the three cases. A time series comparison with buoy for the months March-May 2005 for the two representative locations (DS5 and DS7 buoys) is shown in figure 4 . The contribution of swell towards the overestimation of $\mathrm{H}_{\mathrm{s}}$ is very clear from both the cases. A high degree of overestimation is seen in the Arabian Sea buoy compared to the Bay of Bengal buoy. One dimensional frequency spectrum comparison is shown in figure 5 as an additional support to the above-mentioned overestimation of the swells. As Rogers et al. (2005) pointed out, a possible reason for this inaccuracy in swell height prediction can be the physics of swell attenuation, which is not expected to be accurate in third-generation models. The work of Ardhuin et al. (2009) shows swell dissipation using synthetic aperture radar observations which also supports the inaccuracies of swells in numerical models. Interestingly, a very good agreement of $\mathrm{wH}_{\mathrm{s}}$ can be seen in all the three cases.

Towards a detailed analysis of the performance of the winds in different wind conditions and its impact on wave parameters, error statistics analysis has been performed for data bins with respect to the buoy measured wind speed, $\mathrm{H}_{\mathrm{s}}$ and $\mathrm{T}_{\mathrm{m}}$. Figure 6 shows the bias and scatter index obtained for data bins with respect to the buoy measured wind speed, $\mathrm{H}_{\mathrm{s}}, \mathrm{sH}_{\mathrm{s}}, \mathrm{wH}_{\mathrm{s}}$ and $\mathrm{T}_{\mathrm{m}}$. From the figure it can be seen that, among the three winds,
EC wind shows a very small positive bias in the range $0-5 \mathrm{~m} / \mathrm{s}$ and thereafter an increasing trend of negative bias whereas NQ wind shows a high positive bias in the range $0-5 \mathrm{~m} / \mathrm{s}$ and thereafter a small negative bias in the high range. EQ winds followed the trend of EC winds in the low range and NQ winds in the high wind speed range. All the three wind fields showed an underestimation of wind speed for the high values. A study of the effect of observation errors by Tolman (1998) also states that the bin averaged analysis systematically underestimates extreme wind speeds. This bias trend appearing in wind speeds got clearly reflected in bias trend of $\mathrm{H}_{\mathrm{s}}$. In the low wave height range (up to $1.5 \mathrm{~m}$ ), SW-EC $\mathrm{H}_{\mathrm{s}}$ showed small positive bias and thereafter negative bias with an increasing trend. Interestingly, $\mathrm{SW}-\mathrm{NQ} \mathrm{H}_{\mathrm{s}}$ showed a very small negative bias and very small scatter index in the high wave conditions. SW-EQ $\mathrm{H}_{\mathrm{s}}$ showed a trend very close to the trend of SW-NQ $\mathrm{H}_{\mathrm{s}}$ except at the low range. In the case of wave periods $\mathrm{SW}-\mathrm{NQ} \mathrm{T}_{\mathrm{m}}$ has a positive bias in low wave period range. SW-EQ $T_{m}$ and SW-EC $T_{m}$ showed almost similar trends. In the selected dataset $50 \%$ of the data points were in the wind speed range of $0-5 \mathrm{~m} / \mathrm{s}$ and $H_{\mathrm{s}}$ range of $1-1.5 \mathrm{~m}$. In the low wind speed range EC wind shows a good agreement with buoy as well as altimeter measurements. This is the main reason for the best results of SW-EC wave parameters. (a)
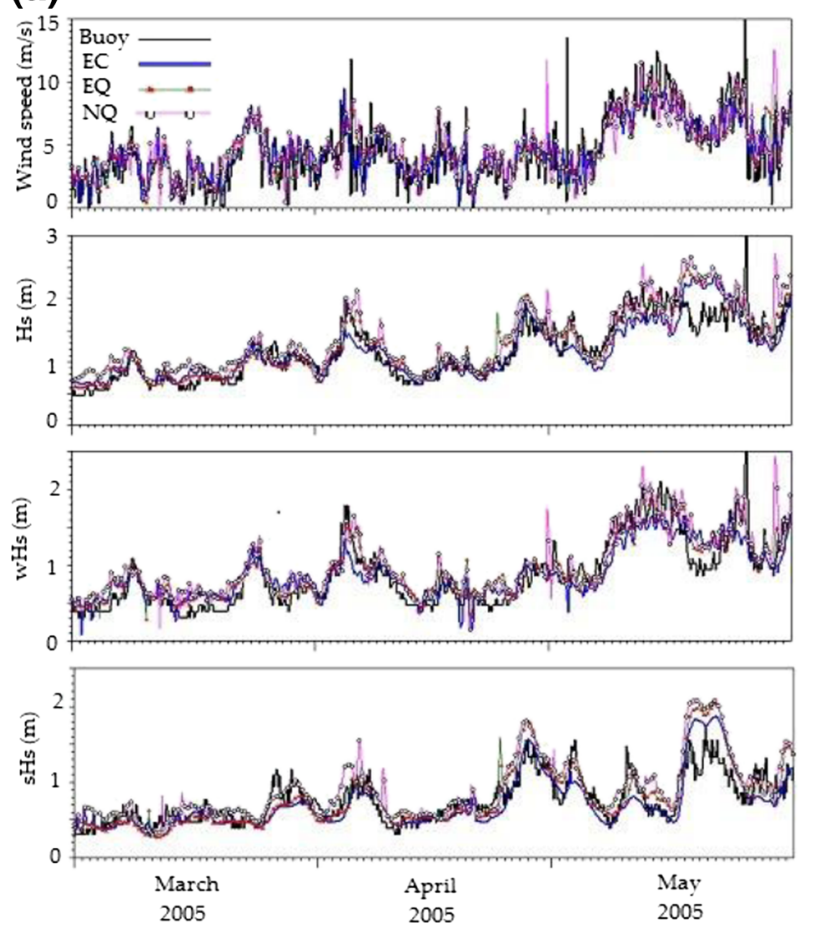

(b)
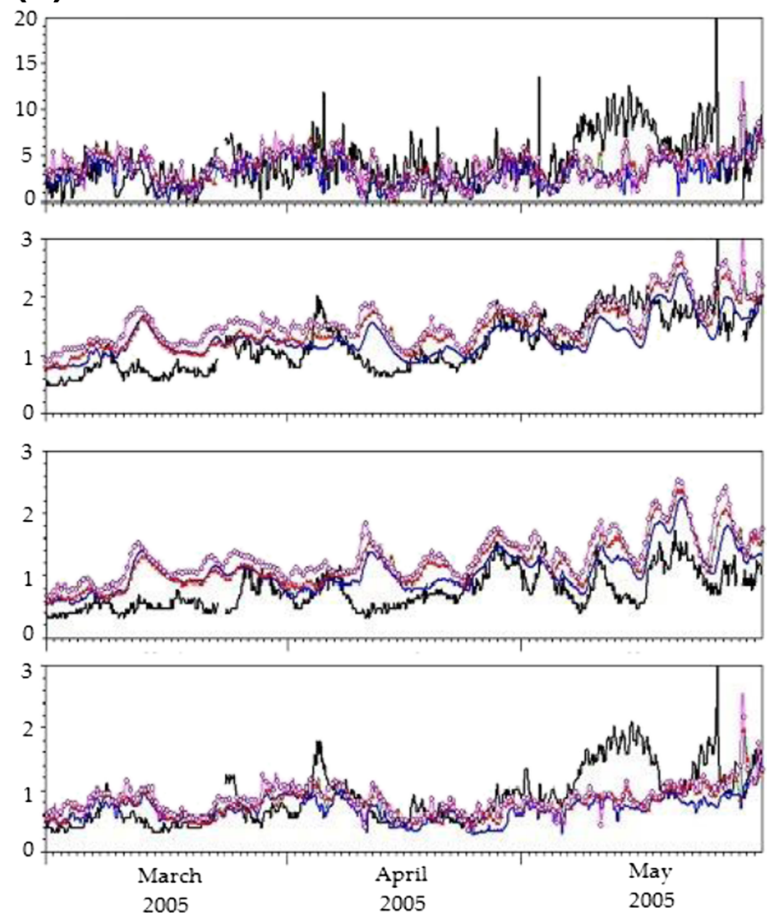

Figure 4. Comparison of measured and forecasted one dimensional wave spectra at DS5 buoy location during (a) April 30 09:00 UTC (b) May 05 18:00 UTC and (c) May 11 03:00 UTC. 
The buoys selected for comparison provided sparse and discontinuous data. So, for a detailed analysis, the model derived parameters $\mathrm{H}_{\mathrm{s}}$ and $\mathrm{T}_{\mathrm{m}}$ have been compared with altimeter derived $\mathrm{H}_{\mathrm{s}}$ and $\mathrm{T}_{\mathrm{m}}$. For comparison purpose, model points within $25 \mathrm{~km}$ of altimeter passes and within 1 hour of the altimeter observations have been used. Neither $\mathrm{sH}_{\mathrm{s}}$ nor $\mathrm{wH}_{\mathrm{s}}$ can be estimated from altimeter data. So the comparison is limited to $\mathrm{H}_{\mathrm{s}}$ and $\mathrm{T}_{\mathrm{m}}$. Error statistics analysis has been carried out separately for the north Indian Ocean and the full Indian Ocean. From table 2 it can be seen that the error statistics of north Indian Ocean is quite similar to the error statistics obtained from buoy comparison. In the altimeter comparison the EC winds show low RMSE, bias, and SI compared to blended winds. It is observed that both the domains show similar trends in all the parameters. The bias trend of wave parameters was positive at the low wave height and negative for the high ones for both the domains. Figure 7 shows the bias and SI obtained for data bins of parameters, wind speed, $\mathrm{H}_{\mathrm{s}}$ and $\mathrm{T}_{\mathrm{m}}$ for north Indian Ocean. Indian Ocean also shows similar trends.

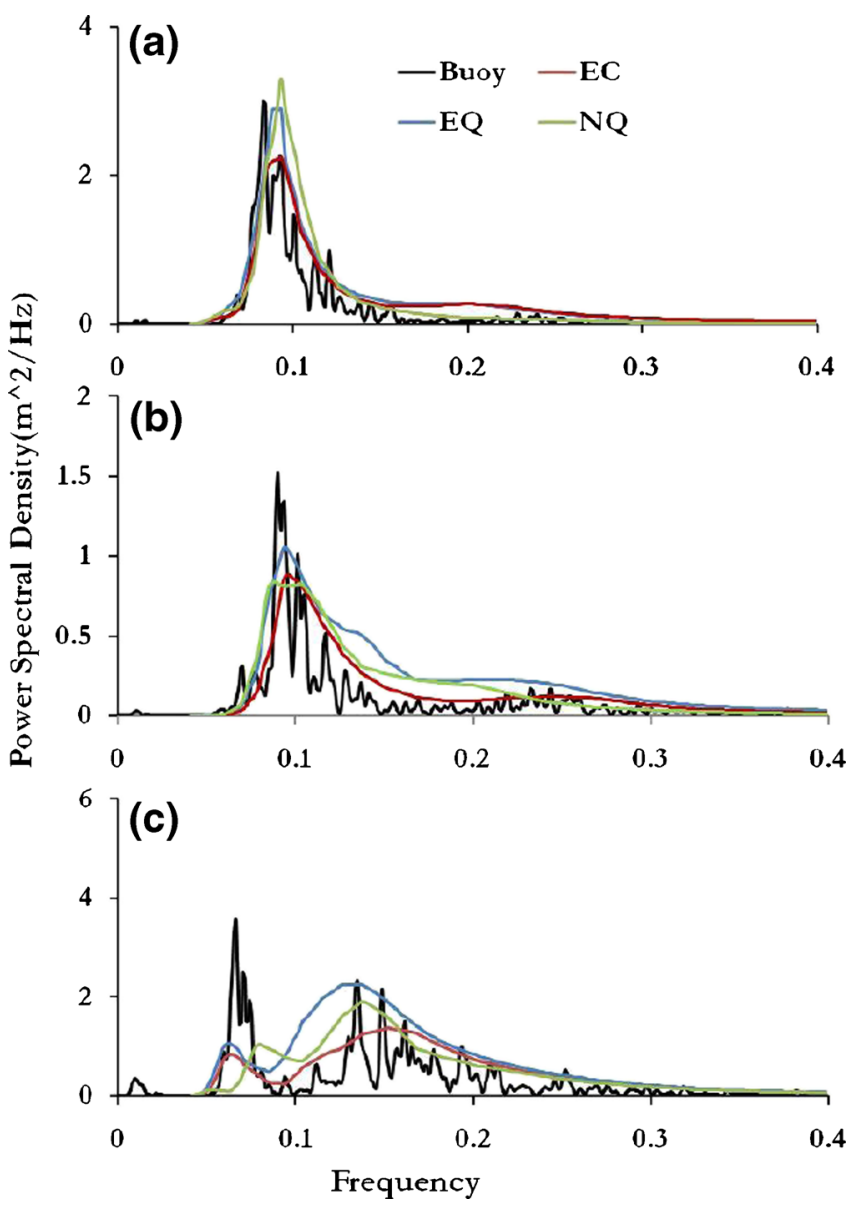

Figure 5. Time series comparison of model simulated wave parameters with buoy data (a) Arabian Sea (DS5) and (b) Bay of Bengal (DS7).

\subsection{Impact of diurnal variation of winds}

The diurnal variation of winds has a profound effect on meteorology and oceanography of coastal areas. After the withdrawal of the Indian summer monsoon and until onset of the next monsoon (November-May), winds in the coastal regions are dominated by sea breeze. Whenever the large scale winds are not present, the diurnal variation of wind has an impact. However, the characteristics of diurnal variations are very clear in the transition months (February-April), the period of transition between the winter and summer monsoons (Aparna et al. 2005). The past study of Neetu et al. (2006) for the west coast of India also shows significant impact of sea breeze on the
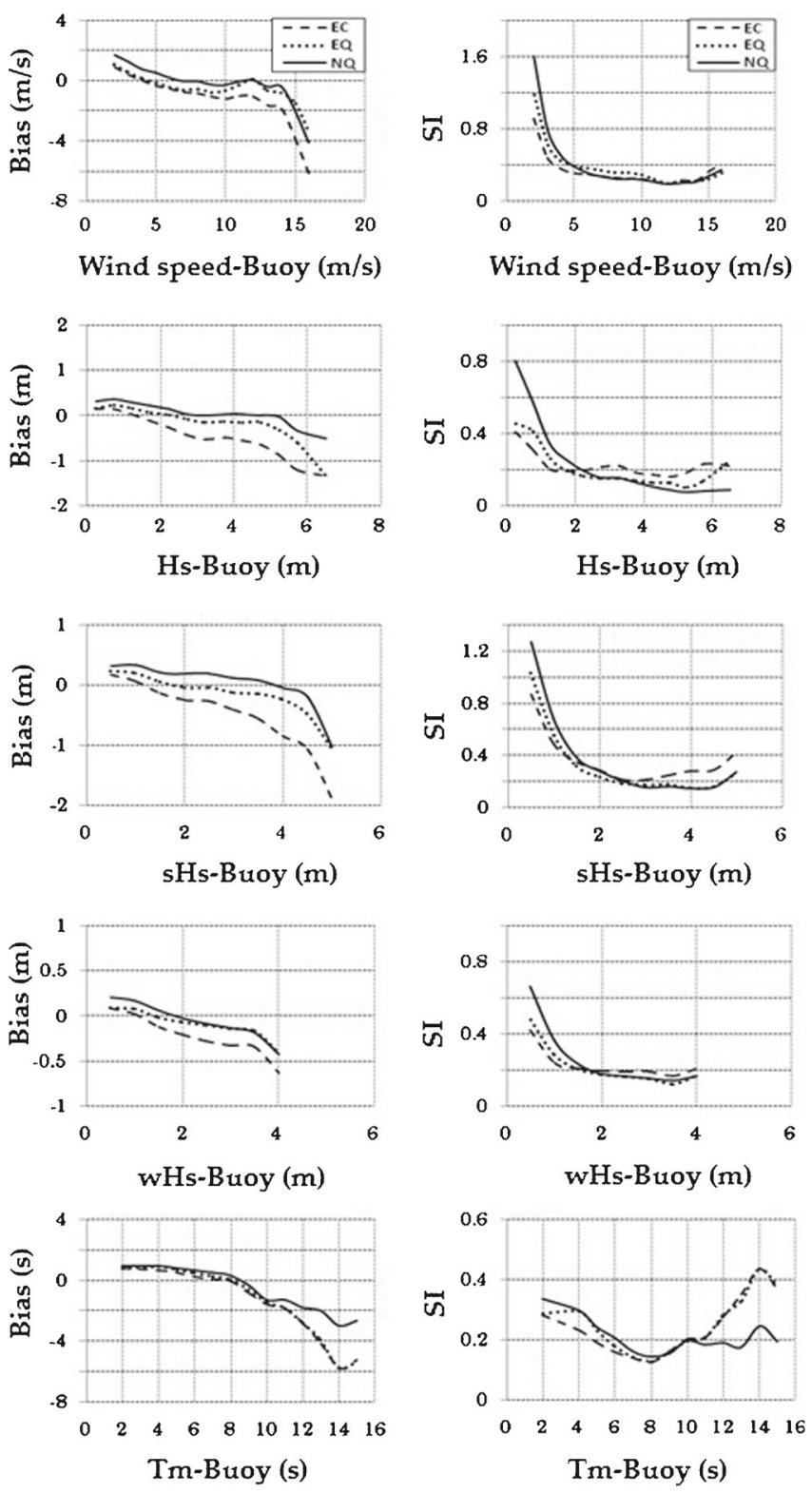

Figure 6. Bias and scatter index (SI) obtained for data bins with respect to buoy measurements for the north Indian Ocean. 
Table 2. Error statistics for the altimeter comparison for the North Indian Ocean.

\begin{tabular}{llllllll}
\hline North Indian Ocean & & Bias & RMSE & SI & $r$ & Mean & Std \\
\hline Wind speed (m/s) & Jason1 & & & & & 6.22 & 2.66 \\
& SW-EC & 0.18 & 1.28 & 0.21 & 0.89 & 6.39 & 2.81 \\
& SW-EQ & 0.38 & 1.32 & 0.21 & 0.89 & 6.60 & 2.77 \\
& SW-NQ & 0.45 & 1.70 & 0.27 & 0.83 & 6.67 & 2.94 \\
& & & & & & 1.67 & 0.95 \\
$\mathrm{H}_{\mathrm{S}}(\mathrm{m})$ & Jason1 & & & & & & \\
& SW-EC & 0.04 & 0.34 & 0.21 & 0.93 & 1.72 & 0.84 \\
& SW-EQ & 0.17 & 0.40 & 0.24 & 0.92 & 1.84 & 0.86 \\
& SW-NQ & 0.31 & 0.53 & 0.31 & 0.9 & 1.99 & 0.91 \\
$\mathrm{~T}$ & & & & & & & \\
& Jason1 & & & & & 5.87 & 0.95 \\
& SW-EC & 0.04 & 0.85 & 0.15 & 0.73 & 5.85 & 1.25 \\
& SW-EQ & 0.23 & 0.90 & 0.15 & 0.73 & 6.07 & 1.27 \\
& SW-NQ & 0.53 & 1.08 & 0.18 & 0.71 & 6.25 & 1.34 \\
\hline
\end{tabular}
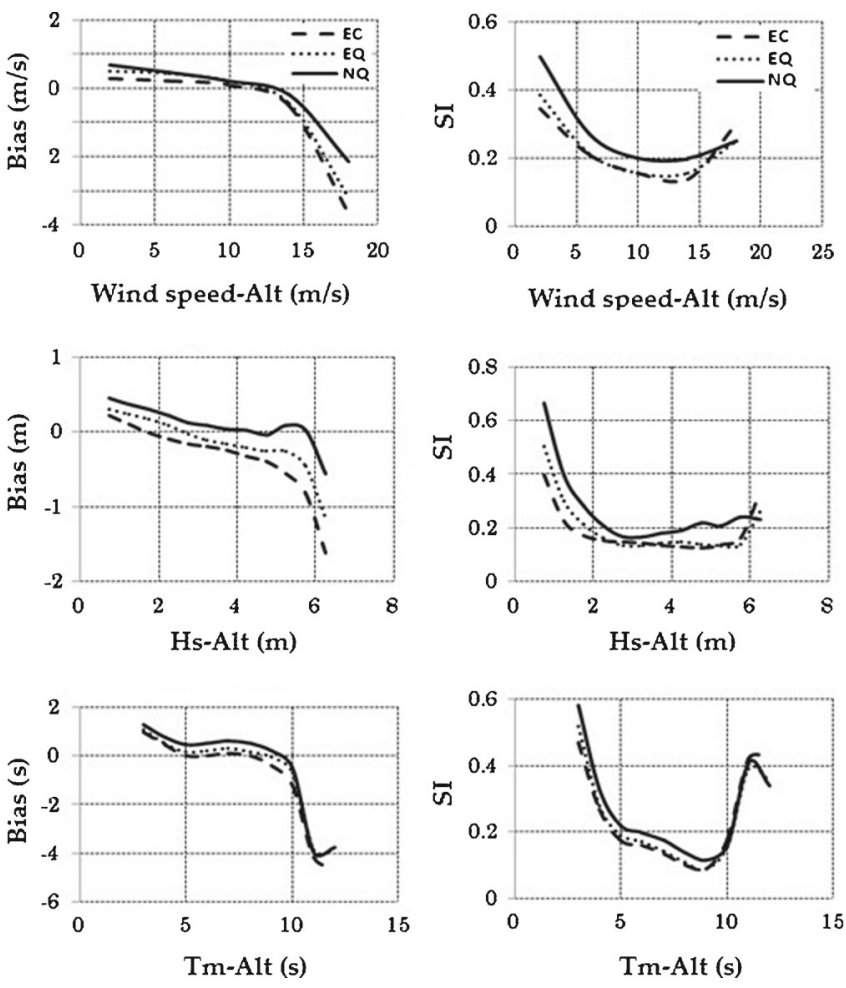

Figure 7. Bias and scatter index (SI) obtained for data bins with respect to altimeter measurements for the north Indian Ocean.

daily cycle of the sea state near the coast. In the pre-southwest monsoon months the predominant winds over the Arabian Sea between latitudes $5^{\circ} \mathrm{N}$ and $20^{\circ} \mathrm{N}$ change gradually from between north-east and north-west to between northwest and west. The change in the wind direction with subsequent development of sea breeze causes a change in the wave direction more towards north-west during this period (Reddy 2001). High resolution wind fields are required to resolve the fine details of land-sea breeze systems. Since it is very difficult to have the high resolution surface winds as forcings of wave models, the impact of diurnal variation of winds has been studied using the above-described wind fields. The aim of this experiment is to explore the possibility of studying the impact of diurnal variation of winds on coastal waves using numerical models. To study the impact of the three wind products during sea breeze phase, we have selected 4 weeks of active sea breeze period from February 15-March 15 of the year 2005. For the comparison, 3-hourly data of a shallow water buoy located in the Arabian Sea at the latitude $15.49^{\circ} \mathrm{N}$ and longitude $73.75^{\circ} \mathrm{E}$ was selected (red mark in figure 1 ). The sea breeze dominance was clear in this buoy during pre-monsoon months. Figure 8(a) shows wind speed and direction as well as the changes in $\mathrm{H}_{\mathrm{s}}$ and $\mathrm{T}_{\mathrm{m}}$ observed in SW3 buoy. It is observed that the sea breeze is most prevalent between 12 and 21 hours (local time) and typically produces 1-1.5 $\mathrm{m}$ high waves. Masselink and Pattiarchi (1998) pointed out that, following the onset of sea breeze, addition of locally generated wind waves to background swell resulted in an increase in wave height and a decrease in mean wave period. The super imposition of wind sea and swell cause a decrease in the mean wave period. During the sea breeze the local winds are stronger than the synoptic winds and due to that, the wave height increases. The role of wind speed on the wave growth decreases when the wind direction varies with time (Komen et al. 1994). When the wind and wave directions are opposite to each other (land breeze), the wind applies an opposing stress against the waves and therefore the wave 

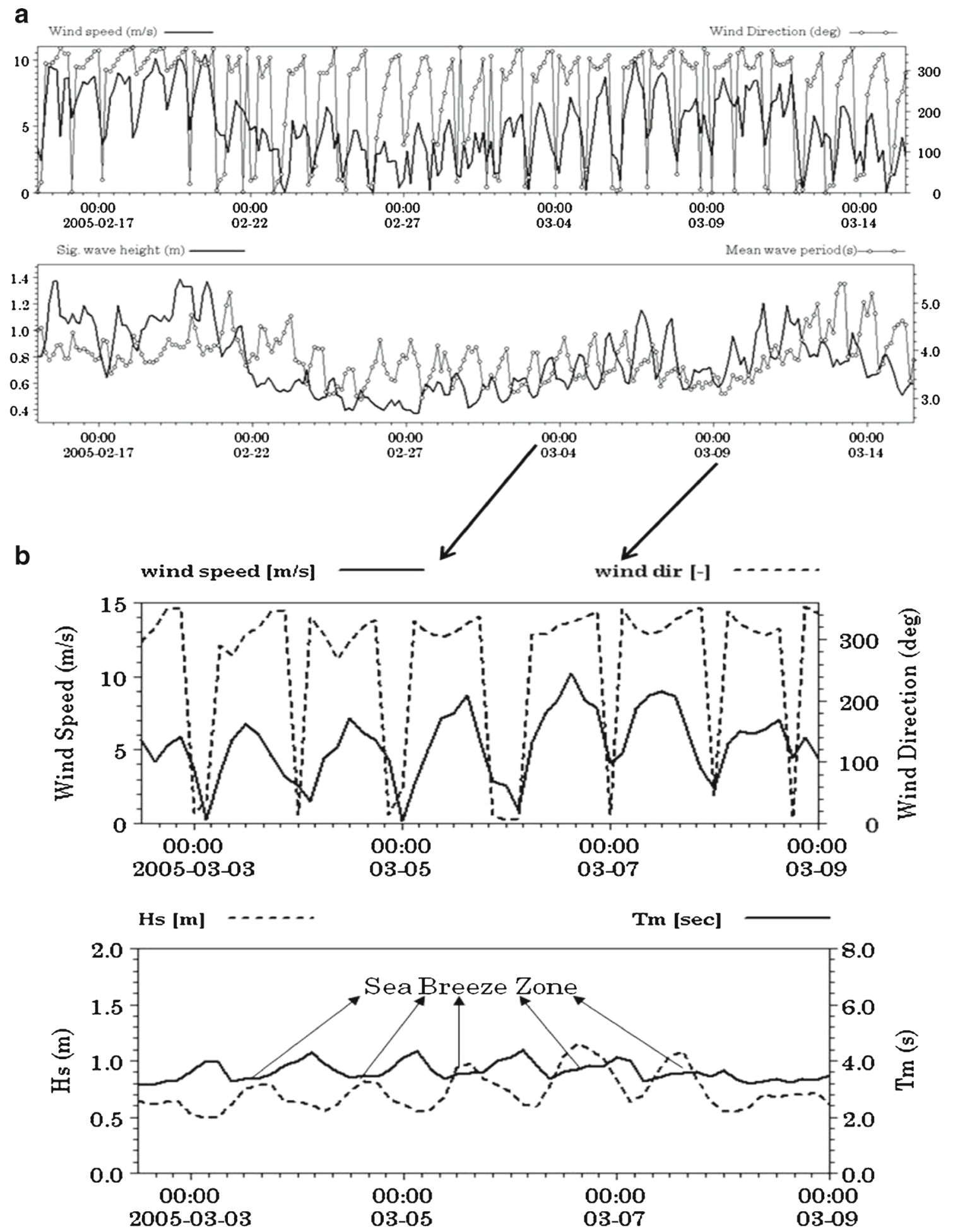

Figure 8. Wind speed and directional change during sea breeze and corresponding wave height and wave period changes observed in SW3 buoy.

height growth is negative. This type of variation in $\mathrm{H}_{\mathrm{s}}$ and $\mathrm{T}_{\mathrm{m}}$ is very clear in figure $8(\mathrm{~b})$. A comparison of wind speeds has been made to see the disparities in the winds during sea breeze in figure 9 . From this figure, it can be seen that only the NQ wind was able to produce the wind speed variations during active sea breeze. The other two winds, namely EC and EQ winds highly underestimated the wind speed. The disparity in winds might be because of the very weak winds present in the western coastal regions of India in these two winds (figure 2a) and was clearly reflected 


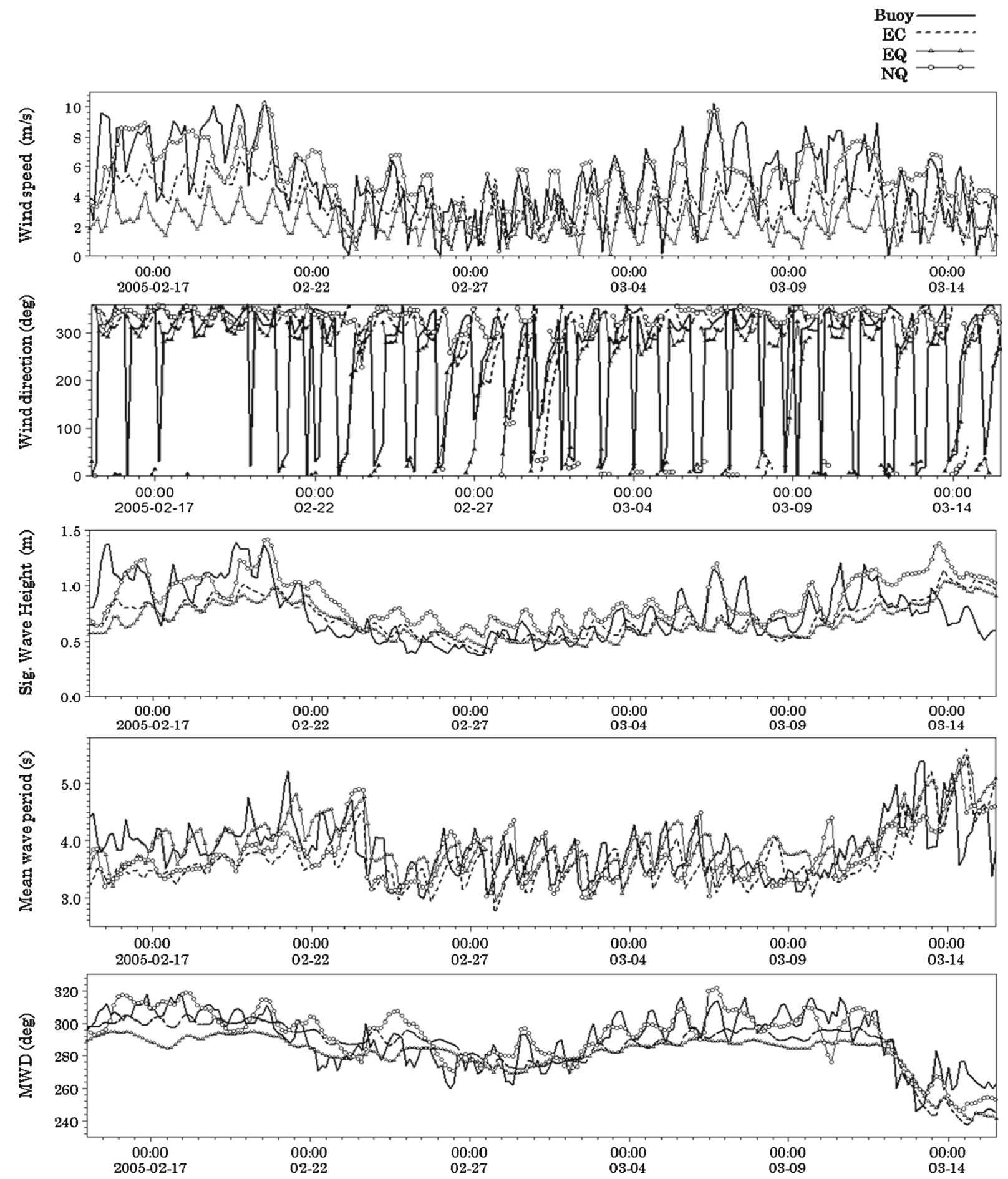

Figure 9 . Wind speed, $\mathrm{H}_{\mathrm{s}}, \mathrm{T}_{\mathrm{m}}$ and directional changes during sea breeze.

in the wave model results. The increase in the wave height and decrease in the wave period associated with sea breeze is very clear in SW-NQ results. The directional change during sea breeze was very clear in the SW-NQ mean wave direction (MWD). As in the case of wind speed, the EC and EQ could not faithfully reproduce the variations in the wave parameters. This clearly shows that the NQ wind fields can be used for studying the impact of diurnal variation of winds on coastal waves in the absence of high resolution wind fields. This experiment also shows the significant impact of diurnal variation of winds on coastal waves. So for an accurate wave prediction in the coastal regions, this diurnal variation of wind has to be included. 


\subsection{Impact during high wind conditions}

As far as the wave modeling is concerned, another challenge is the wave prediction during tropical cyclone. In the year 2005, during the period November 28-December 22, there were two cyclones and one deep depression in the Bay of Bengal. The first cyclone was 'Baaz' during the period November 28-December 2 with a maximum wind speed of $24 \mathrm{~m} / \mathrm{s}$. Four days later another cyclone 'Fanoos' developed in the same region with peak intensity $27 \mathrm{~m} / \mathrm{s}$ and existed for 4 days from December 6-10. Again after 5 days another depression was formed in the southeastern Bay of Bengal. This depression existed between December 15 and 22 and the maximum wind speed was around $15 \mathrm{~m} / \mathrm{s}$. The growth and decay of waves during these events were observed in the buoy MB10, off Mahabalipuram, located at $84.98^{\circ} \mathrm{E}$ longitude and $12.54^{\circ} \mathrm{N}$ latitude. Figure 10 shows the location of

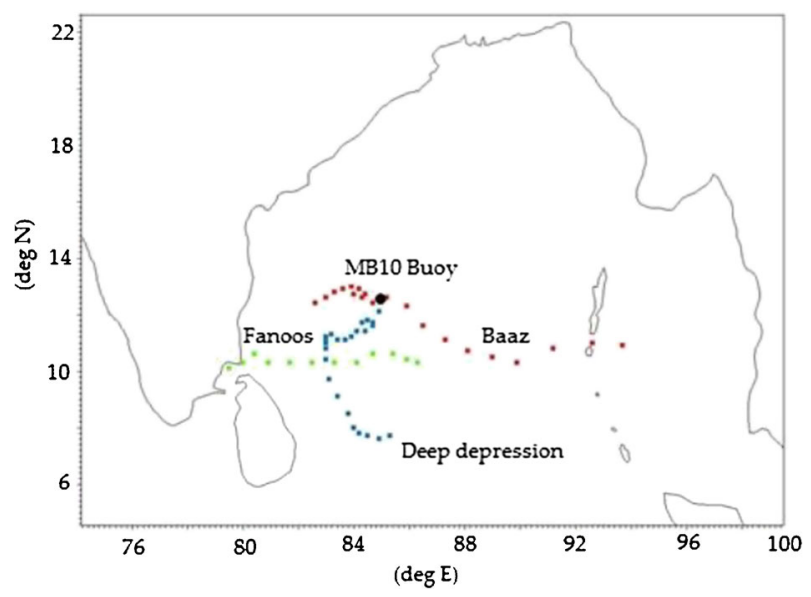

Figure 10. Cyclone tracks and location of the buoy. buoy and the cyclone tracks. A comparison of wind speed and wave height has been carried out to see the impact of different winds in the extreme conditions. Figure 11 shows a time series comparison of wind speed and wave height with buoy. In the wind speed comparison, we can see the clear underestimation of wind speed in the EC winds. This supported the conclusion drawn from the analysis of error statistics that the EC wind underestimates the wind speed in high wind conditions. The comparison of blended winds shows that both the blended winds were able to show the increase and decrease in the wind speed very clearly. There was not much difference in the performance. As in the case of wind speed, the SW-EC $\mathrm{H}_{\mathrm{s}}$ also showed a clear underestimation of wave height of the order of 1-2 m. A good agreement at the low wave heights has also been observed in the comparison. This also supports our earlier conclusion. The blended winds were able to produce the growth and decay of waves very clearly in all the three cases. This once again proves the capability of blended winds to produce reasonably accurate wave model results during high wind conditions.

\section{Conclusions}

The present study is concerned with an assessment of the impact of various wind forcings on wave model results. More specifically, three different wind fields were used to drive MIKE21 SW model in the Indian Ocean region and the impact was analyzed via a comparison of the results with in situ observed and remotely sensed counterparts of model-generated parameters. A high degree of
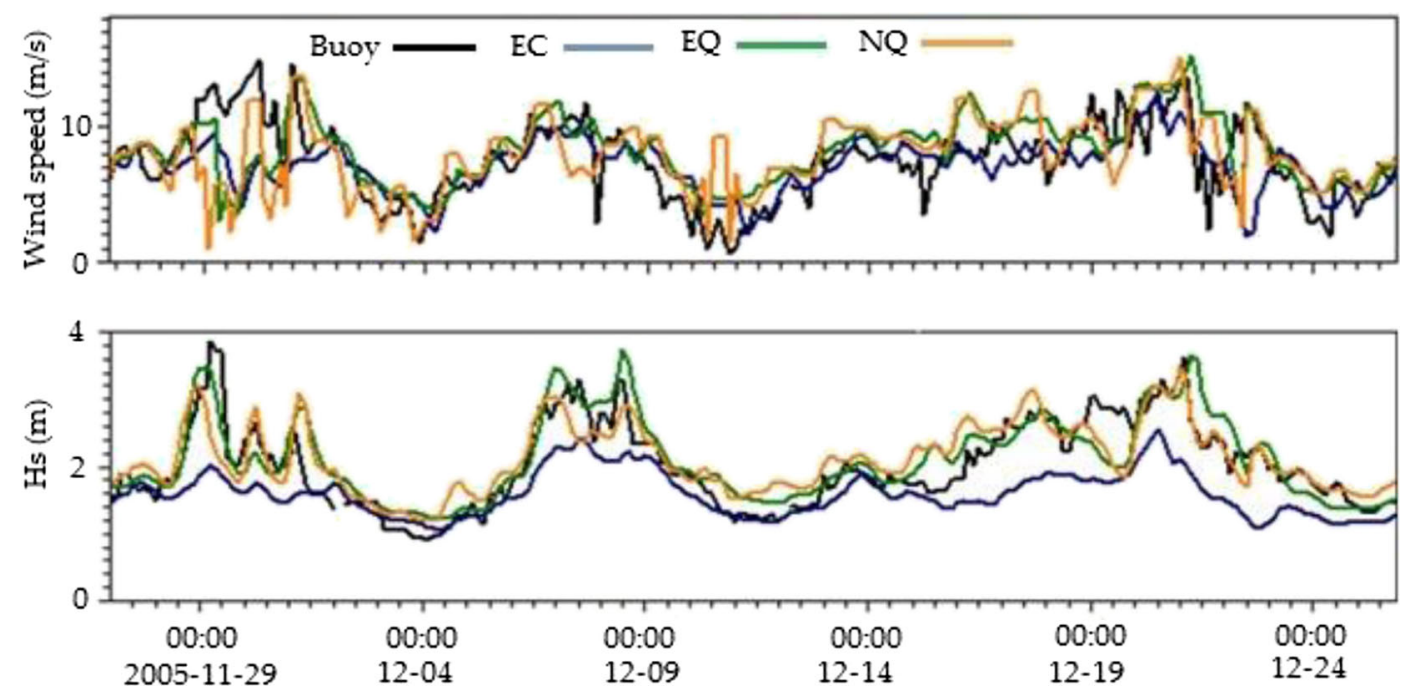

Figure 11. Wind speed and wave height variations during different cyclonic events. 
spatial variability was evident in the blended wind fields, which was conspicuous by its absence in the analyzed EC winds. It could be noted that there is an underestimation of the SW-EC wave parameters, possibly due to the relative smoothness of the EC winds. It is highly probable that the blended winds with more variable wind fields could reduce this negative bias in the wave model results. This is more vividly brought to focus while analyzing the results in the cyclonic condition. It was found that blended wind fields generated more realistic wave fields over the areas within the cyclonic influence than the analyzed EC winds. During cyclonic conditions, both the blended winds were able to produce the growth and decay of waves very clearly. Apart from the analysis of cyclone cases, the impact of sea breeze was also studied. This impact was reflected in the NQ wind fields, which were able to depict the diurnal variation of winds, dominant in the coastal regions, especially near the west coast of India. This diurnal variation was found to have a significant impact on wave model results.

Considering all the pros and cons, it can be conclusively said that the result of the study has undoubtedly come in favour of the blended wind fields, in an overall sense. Among the two blended winds, EQ wind performed marginally better, possibly because the MIKE $21 \mathrm{SW}$ model is tuned to this wind. However, the impact of sea breeze is better picked up by the NQ winds in the west coast. Since the EQ winds and EC winds are low in the west coast of India, these winds could not reproduce the diurnal variations. The analysis has been done only for the year 2005. These results might be valid only for the same. Summarizing, we strongly advocate the use of EQ winds as forcing of MIKE $21 \mathrm{SW}$ in the Indian Ocean region.

\section{Acknowledgements}

This work was done as part of $\mathrm{PhD}$ work of Remya P G while she was at Space Applications Centre. Authors wish to thank the Director, Space Applications Centre, the Deputy Director, Earth, Ocean, Atmosphere, Planetary Sciences and Applications Area and the Group Director, Atmospheric and Oceanic Sciences Group, for motivation and encouragement. The in-situ data for the analysis was provided by National Institute of Ocean Technology, MoES, India. The authors wish to thank Delft Institute for Earth Oriented Space Research Radar Altimeter Database system (http://rads. tudelft.nl/rads/rads.shtml) for providing radar altimeter data. QSCAT/NCEP blended wind data were obtained through the GEBCO Digital Atlas published by the British Oceanographic Data
Centre on behalf of IOC and IHO, 2003; website http://dss.ucar.edu/datasets/ds744.4/. Authors also wish to thank two anonymous reviewers for their valuable suggestions. The corresponding author would like to thank the Director, Indian National Centre for Ocean Information Services, Ministry of Earth Sciences, Govt. of India, Hyderabad, for encouragement and support. This is INCOIS contribution no. 195.

\section{References}

Aparna M, Shetye S R, Shankar D, Shenoi S S C, Mehra P and Desai R G P 2005 Estimating the seaward extent of sea breeze from QuikSCAT scatterometry; Geophys. Res. Lett. 32 L1360, doi: 10.1029/2005GL023107.

Ardhuin Fabrice, Chapron Bertrand and Collard Fabrice 2009 Observation of swell dissipation across oceans; Geophys. Res. Lett. 36(L06607) 1-5, doi: 10.1029/ 2008GL037030.

Battjes J A and Janssen J P F M 1978 Energy loss and setup due to wave breaking of random waves; In: Proc. 16th Int. Conf. Costal Eng., ASCE, pp. 569-587.

Bentamy A, Ayina H-L, Queffeulou P, Croize-Fillon D and Kerbaol V 2007 Improved near real time surface wind resolution over the Mediterranean Sea; Ocean Sci. 3(2) 259-271.

Bidlot J-R, Holmes D J, Wittmann P A, Lalbeharry R and Chen H S 2002 Intercomparison of the performance of operational ocean wave forecasting systems with buoy data; Wea. Forecast. 17 287-310.

Cavaleri L 1994 Applications to wave hindcasting and forecasting; Chapter IV; In: Dynamics and Modeling of Ocean Waves, Cambridge University Press, UK, 532p.

Chin T M, Milliff R F and Large W G 1998 Basin-scale highwave number sea surface wind fields from a multi resolution analysis of scatterometer data; J. Atmos. Oocean. Technol. 15 741-763.

DHI 2005 Mike21 spectral wave module, Scientific documentation; Danish Hydraulic Institute (DHI).

Feng H, Vandemark D, Quilfen Y, Chapron B and Beckley B 2006 Assessment of wind-forcing impact on a global wind-wave model using the topex altimeter; Ocean Eng. 33 1431-1461.

Govindan R, Kumar R, Basu S and Sarkar A 2011 Altimeter derived ocean wave period using genetic algorithm; IEEE Geosci. Rem. Sens. Lett. 8 354-358.

IOC IHO and BODC 2003 Centenary edition of the GEBCO Digital Atlas published on CD-ROM on behalf of the Intergovernmental Oceanographic Commission and the International Hydrographic Organization as part of the General Bathymetric Chart of the Oceans; British Oceanographic Data Centre, Liverpool.

Komen G J, Cavaleri L, Donelan M, Hasselmann K, Hasselmann S and Janssen P A E M 1994 Dynamics and modeling of ocean waves; Cambridge University Press, UK, 560p.

Kumar R et al. 2000 Ocean wave model sensitivity experiments; Preprints, Fifth Pacific Ocean remote sensing Conf. (PORSEC), Goa, India, pp. 801-803.

Masselink G and Pattiarchi C B 1998 The effect of sea breeze on beach morphology surf zone hydrodynamics and sediment resuspension; Mar. Geol. 46 115-135.

Milliff R F, Large W G, Morzel J, Danabasoglu G and Chin T M 1999 Ocean general circulation model sensitivity to 
forcing from scatterometer winds; J. Geophys. Res. C5 $11,337-11,358$.

Milliff R F, Morzel J, Chelton D B and Freilich M H 2004 Wind stress curl and wind stress divergence biases from rain effects on QSCAT surface wind retrievals; J. Atmos. Ocean. Tech. 21 1216-1231.

Neetu S, Shetye S and Chandramohan P 2006 Impact of seabreeze on wind-seas off Goa, west coast of India; J. Earth. Syst. Sci. 115 229-234.

Persson A and Grazzini F 2007 User guide to ECMWF forecast products; Meteorol. Bull. M3(24) 1-46.

Reddy M P M 2001 Descriptive physical oceanography; A A Balkema Publishers, Netherlands, 440p.
Rogers Erick W, Wittmann P A, Wang D W C, Clancy R M and Hsu Y L 2005 Evaluations of global wave prediction at the Fleet Numerical Meteorology and Oceanography Center; Wea. Forecast. 20 745-760.

Sørensen O R, Kofoed-Hansen H, Rugbjerg M and Sørensen L S 2004 A third generation spectral wave model using an unstructured finite volume technique; Proc. 29th Int. Conf. Costal Eng., Lisbon, Portugal.

Tolman 1998 Effects of observation errors in linear regression and bin-average analyses; Quart. J. Roy. Meteorol. Soc. 124 897-917.

Young I R 1999 Wind-generated ocean waves; Elsevier Ocean Engineering Book Series 2. 